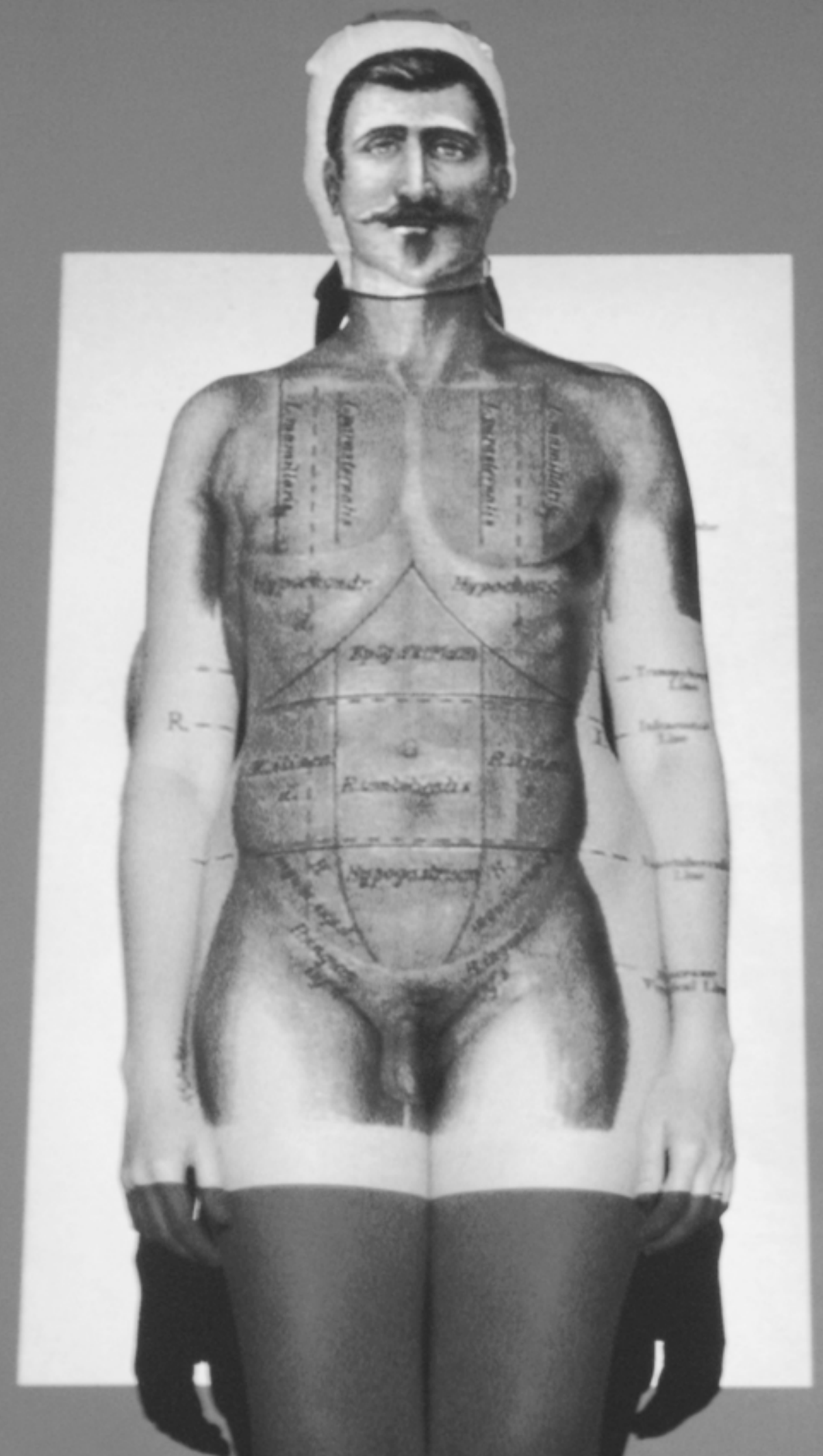




\section{Dramaturgia da carne: uma experiência em performance art}

CLÁUDIA SCHULZ

LUCIANA HARTMANN

Resumo

O presenteartigo intitulado Dramaturgia da Carne: uma experiência em Performance Art, é uma reflexão sobre a performance $4^{\circ}$ Seminário da lista de compras do corpo, que realizei como objeto de estudo para minha pesquisa de mestrado. Aqui farei uma explanação concentrada sobre a prática em si, relatando desde o início do processo criativo até os presentes resultados tecendo algumas considerações vinculadas a experimentação das relações do corpo a projeção de imagens. 


\section{Abstract}

This article entitled Dramaturgy of meat: an experience in Performance Art, is a reflection on the per-

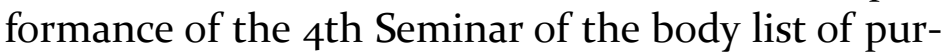
chases that made the object of study for my Masters research. Here an explanation will concentrate on the practice itself, reporting from the beginning of the creative process to the present results weaving some considerations related to testing of the relationship of the body of the projection images. 


\section{A Desarmonia das Vísceras}

Dramaturgia da Carne. Ampliação e dilatação do corpo no tempo e no espaço, horizontalizando a comunhão entre os corpos, prontos ou não para a vivência da (inter)subjetividade desembocando do aguçamento dos sentidos e instintos. Desafiar os limites existentes entre o que é meu e o que é seu. Mostrar meu corpo para você ver o seu.

Na dramaturgia da carne do meu corpo não conheço gramática nem léxico, ele só se decifrou pelo esvaziamento de mim, pelo esvaziamento da forma que vejo e do preenchimento do corpo que sinto. "Fecha os olhos e vê", escreveu James Joyce em seu consagrado romance Ulisses, fecha os olhos e se deixa abalar pela sensação do escuro, do inabitável. Fecha os olhos e deixa o desejo tomar as rédeas da vontade de fazer, de sentir, de olhar.

Dramaturgia da Carne. Guiada pelo repouso e movimento dos silêncios do desejo, digo adeus ao corpo tiranizado pelo espelho e tatuo o texto da pele, meu corpo não mais um estranho, mas um corpo exibido pela fascinação dos obscenos rituais de metamorfose.

Porém, essa escrita subjetiva que só se lê pelos sentidos e que tenta colocar em ação os conflitos do meu corpo, propagandoos em um espaçotempo específico só tornou-se alcançável pela união carnal entre minhas experiências artísticas nos campos das artes cênicas e das artes visuais.

Quando iniciei meu processo artístico teatral busquei enfatizar em meu trabalho o uso experimental do corpo em busca de uma poética que atravessasse e desencadeasse outras potencialidades do mesmo. Nesse sentido, durante cinco anos de academia pude, por meio da colaboração com demais colegas, despojar-me de mim, e vivenciar novas e diferentes maneiras de sentir, ver e moldar meu corpo. Assim, senti que era pela perda das inibições e dos tabus que são imbricados ao corpo é que se dava a experiência. A experiência de um corpo não ficcional, de um corpo errante.

No meu último ano de graduação, no qual cursava a habilitação em Direção Teatral, desenvolvi um projeto intitulado $A$ influência da performance enquanto linguagem nas manifestações cênicas contemporâneas, que resultou num espetáculo teatral, sob minha coordenação. O espetáculo foi criado a partir do texto Caim (1821), do dramaturgo inglês e romântico George Gordon Byron. O espetáculo chamou-se http://www.projeto.caim, e 
foi levado a público no dia 31 de janeiro de 2006. Possuía como suporte de pesquisa teórica e prática três aspectos destacados da linguagem da performance art que instigavam-me enquanto pesquisadora: a proposta de fazer com que os atores realizassem um processo de recodificação das questões existenciais humanas contidas no texto tendo como ponto de partida o significante para se alcançar um significado; o uso de multimeios que abrangia o campo da fotografia, do vídeo por meio de projeções e do som e a criação do encenador por meio da Collage através do processo de justaposição destes multimeios.

Destes três elementos trabalhados durante um ano de pesquisa, salientou-se meu interesse pelo uso de multimeios, pois a partir dele (plural) é que se desencadeava a proposta de interação com elementos extra-teatrais midiatizados. Foi com base neste aspecto que se processou a experimentação e a criação dos atores com as imagens e vídeos desenvolvidos por mim, buscando realizar uma interatividade através do diálogo artístico entre o homem e a tecnologia. Nesse sentido, o processo de criação do espetáculo foi instigante, pois estávamos (meus atores, equipe técnica e eu) adentrando em um campo não experimentado até então, com isso cada descoberta relacionada às possíveis relações entre os corpos dos atores e as imagens que era projetadas nos lançavam inquietações, não havia limites. Dentre os aspectos que foram explorados destaco a possibilidade de tridimensionalizar, por meio do corpo, uma imagem bidimensional como também poder lhe atribuir uma nova forma, ritmo e densidade, como se a partir dessa imagem, pudéssemos criar um terceiro "corpo".

Buscando dar procedência ao trabalho iniciado em 2005, no qual me mantinha, de certa maneira, restringida à minha função de diretora passei a desenvolver a atual pesquisa no intuito de vivenciar em meu corpo aquilo que havia proposto para meus atores durante o processo de criação do espetáculo. Assim, propus como eixo central da pesquisa que venho desenvolvendo no Programa de Pós-Graduação em Artes Visuais -UFSM, o desenvolvimento de uma performance multimídia, que denominei de $4^{\circ}$ Seminário sobre a lista de compras do corpo, a qual foi elaborada a partir de experimentações práticas de relação do meu corpo com projeções de imagens (fotografias e vídeos) e, concomitantemente, a elaboração de um estudo e reflexão sobre os fundamentos e possíveis poéticas do trabalho. 
Nesse sentido, Dramaturgia da Carne, desde seu embrião se trata de um trabalho plural e interdisciplinar, pois procura entrelaçar e horizontalizar às percepções das diferentes áreas artísticas (teatro e artes visuais) assim como ariscar-se no campo da filosofia e da antropologia para enfatizar ainda mais essa possível relação e fundamentação na arte efêmera que se perpetua pela suspensão temporal na memória de cada testemunho.

A dramaturgia escrita no corpo desse artigo pretende desmembrar e desmistificar a presença do corpo contemporâneo. Partindo da idéia de que com o desenvolvimento da tecnologia eletrônica o ser humano se viu compelido a relacionar-se com os novos meios, (rádio, a televisão, o cinema, o computador e a internet, entre outros) e que esses passaram a influenciar seu comportamento, suas relações sociais e culturais e a sua consciência corporal, detectou-se que ainda há, entre os desdobramentos desta nova situação, a figuração de um certo mal-estar do indivíduo em relação ao seu próprio corpo. Submetido cada vez mais a contrastes que relativizam sua presença física e a natureza material de seu trabalho, ao mesmo tempo, o ser humano vê-se frente a novos leques de possibilidades, uma vez que o desenvolvimento das culturas cibernéticas funda também uma era de alcances criativos antes inimagináveis.

A partir desta constatação, Dramaturgia da Carne visou, acima de tudo, desenvolver uma pesquisa experimental que almeja alcançar uma aliança entre arte e cultura digital, tendo como foco principal a interação entre corpo e projeções, buscando realizar uma interatividade entre o espaço-tempo real (corpo), dotado e explorado por sua materialidade, com espaçotempo virtual (projeções/web), visando obter o fenômeno da imagem. A imagem, aqui, vista como propulsora de diferentes sensações e imbricada por signos que desencadeiem variáveis "leituras" sem a preocupação de ordenar caminhos, mas de funcionar como uma rede.

Dramaturgia da Carne é o desejo de alargar os horizontes e amplificar as relações entre o homem e as mídias eletrônicas, ou seja, entre o corpo e o vídeo, e buscar alcançar uma abertura entre as formas de expressão artísticas, hibridizando-as, diminuindo a distância entre o virtual e o real, criando artistas mediadores de processos sociais e culturais contemporâneos. 


\section{A criação de uma pele: descrição do processo criativo}

"Compreendeu que o empenho de modelar a matéria incoerente e vertiginosa de que os sonhos são feitos é o mais árduo que um varão pode empreender, embora penetre todos os enigmas da ordem superior e da inferior: muito mais árduo que tecer uma corda de areia ou que amolar o vento sem rosto. Compreendeu que um fracasso inicial era inevitáve" (BORGES, 2007, p. 49).

Acredito que escrever sobre o que se faz é cair em queda livre num infinito de enigmas indecifráveis, é realmente empenharse em amolar o vento sem rosto borgiano; é estar perdido em um labirinto onde as paredes são a nossa própria pele, nossos próprios desejos e ansiedades, nossos sonhos. O trabalho artístico, a arte em um âmbito geral, propicia àquele que se dedica a ela um universo de ínfimas fragrâncias, permitindo ao artista uma conversa infinita com a "matéria incoerente e vertiginosa de que os sonhos são feitos" (BORGES, 2007, p. 49).

Porém, mesmo em queda livre, o desafio de andar sob o fio de uma navalha parece liberar uma adrenalina contida na instigante insegurança de ter de escrever sobre aquilo que não se tem certeza, daquilo que também depende de outro para ser olhado. Mas é nesse campo, no campo do incerto e do invisível, que temos algo a dizer.

A performance $4^{\circ}$ Seminário sobre a lista de compras do corpo consistiu na projeção, em três telões, de fotografias de registro tiradas durante o processo criativo e a minha presença ativa durante sua realização (teve duração de 20 minuos) com a música que foi composta e executada por uma banda e, nos 5 minutos finais, a interação de meu corpo com uma imagem selecionada previamente. A performance foi transmitida pela web, sendo que não havia público no local de sua realização, somente online (ver Figura o1).

Durante meu processo criativo experimental que culminou na elaboração da performance $4^{\circ}$ Seminário sobre a lista de compras do corpo, empreguei a metodologia que prioriza a transmissão do conhecimento por meio dos sentidos, partindo da "prática à teoria" (PLAZA e TAVARES, 1998, p. 103). Ciente das diversas possibilidades que o meio eletrônico, ou seja, as projeções e a própria manipulação de instrumentos eletrônicos somados ao corpo podem gerar, o processo de criação foi ocor- 
rendo de maneira dinâmica desencadeando novas descobertas de forma prazerosa e surpreendente. Surpreendente pois, como afirma Plaza e Tavares (1998, p. 104) , no ato da criação a experimentação que surge das descobertas e impõem-se como elemento propulsor do insigh. Na medida em que foi ocorrendo à interatividade entre meu corpo e as projeções, delineou-se um diálogo entre meu corpo e com a tecnologia, materializando esta dialética pela concretização da imagem - que possuí o objetivo de ampliar o lugar do imaginário do interator. Assim sendo, a integração e o diálogo entre o espaço-tempo real (corpo) com o espaço tempo-virtual (projeção/ web) concretizou-se de forma imediata, não havendo cisão entre a pergunta e a resposta estabelecida pelo diálogo.

Disposição dos elementos da web performance $4^{\circ}$ Seminário sobre a lista de compras. Anfiteatro Caixa Preta

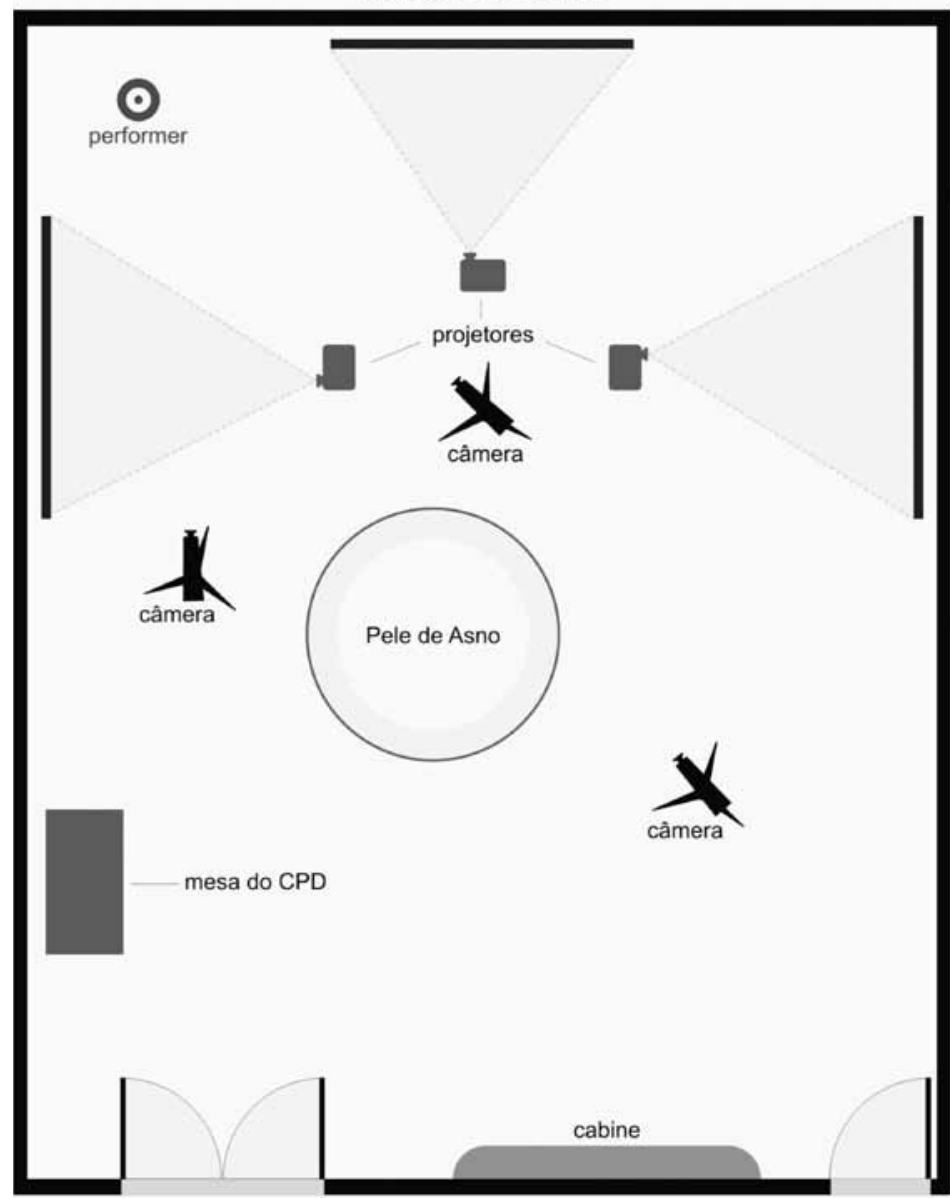

Figura 01

Esquema da estruturação de montagem da performance $-4^{\circ}$ Seminário sobre a lista de compras do corpo 
A partir destas características intrínsecas ao processo de criação experimental pode-se afirmar que este não é um fim em si mesmo, apenas "... incita a desmembramentos infinitos, que são as possibilidades de reler o mundo" (COHEN, 1989, p. 64). Segundo Plaza e Tavares (1998, p. 103) o método do processo de criação experimental “... trabalha com o conhecimento transmitido pelos sentidos". Assim, ao recriar a realidade, busca-se possibilitar ao interator novas leituras da vida a partir de seu aparelho sensório criando uma aliança com o que Medeiros (2005) nos coloca sobre a aisthesis.

Assim, será desenvolvido uma descrição minuciosa referente ao processo de pesquisa, experimentação e criação de material que, posteriormente, foram utilizados para a elaboração e execução de $04^{\circ}$ Seminário sobre a lista de compras do corpo. Encontram-se aqui todos os passos que foram realizados, a partir de anotações a partir de meu diário de bordo. Porém, faz-se necessário esclarecer alguns pontos para que a leitura se torne mais fluída, a partir da explanação do cronograma.

Partindo do pressuposto de que a pesquisa centra sua investigação nas possibilidades advindas da relação do corpo com as projeções de imagens (fotografias e vídeos) estabeleci um cronograma para ser realizado em cinco encontros práticos sob titulo de “Tentativa 1, 2, 3, 4 e 5". Para tanto, delimitei um dia da semana para a realização do encontro que era executado no Teatro Caixa Preta - Espaço Rozane Cardoso/UFSM, sempre nas segundasfeiras das $14 \mathrm{~h}$ às $17 \mathrm{~h}$, local esse que possuía o espaço físico, infraestrutura e equipamentos necessários.

Estruturei cada encontro em cinco partes, que são: a seleção prévia do material ser projetado; montagem do equipamento no espaço; a projeção do material; aquecimento e alongamento corporal e a experimentação do corpo com as projeções.

Os encontros seguiram essa estrutura básica. Porém, como todo processo de criação houve fissuras e lacunas a serem preenchidas e decifradas. Uma das primeiras questões que me barraram logo na primeira tentativa relacionava-se aos tipos de imagens que eu projetava. Comecei projetando imagens aleatórias, sem um leitmotiv. Mas meu corpo não reagiu a elas, não se relacionou com elas. Corpo fechado. Imagem errada.

Nessa “Tentativa 1", acabei testando uma idéia que havia me ocorrido anteriormente: procurei colocar meu corpo nu o mais perto 
possível do projetor, para que servisse de tela para a projeção de um pequeno vídeo. Registrei esse momento com minha câmera digital, o que foi meu segundo problema, pois era difícil fazer e registrar ao mesmo tempo.

Mas afinal o que estava gerando conflito? Porque meu corpo não sentia vontade de interagir com aquelas imagens? Acabei descobrindo que precisava delimitar algum tipo de temática ou assunto que, de certa maneira, fossem elevantes para mim ou que pelo menos me causasse algum tipo de sensação.

Comecei a preparar a "Tentativa2". Nessa preparação meu olhar acabou sendo atravessado por um livro de cinema erótico o qual folhei por uns dias e tomei a decisão de delimitar como leitmotiv da pesquisa cenas eróticas da arte no âmbito geral. Elaborei uma série de lâminas com imagens deste cunho retiradas da internet. Escolhi também alguns objetos que possuíam alguma ligação com meu cotidiano como: meia-calça, batons, sapato de salto, xícara e óculos de sol. Contatei um fotógrafo para que ele fosse junto ao próximo encontro e registrasse o processo, liberandome totalmente para a criação e também solucionando esses dois primeiros obstáculos que surgiram na primeira tentativa.

Neste segundo encontro projetei imagens em partes diferentes de meu corpo nu: nas costas, no peito, na barriga, no corpo inteiro. Estas foram registradas pelo fotógrafo que também fazia pequenas intervenções, orientando a mim e meu corpo em relação ao seu olhar e as próprias imagens. Busquei também interagir com as imagens utilizando-me dos objetos que havia encolhido.

A partir dos registros fotográficos desta "Tentativa 2" é que se tornou possível que eu, enquanto pesquisadora e performer, visualizasse e analisasse mais profundamente minhas tentativas práticas. Como até esse momento eu estava totalmente inserida na pesquisa prática (sendo o objeto), não vislumbrava o que esse registro poderia acrescentar em meu trabalho pelo olhar do outro. Somente a partir dele é que pude reorganizar meus próximos encontros e descobrir e explorar novos terrenos.

Assim, as questões do registro fotográfico e do vídeo tornaramse fundamentais. Mas com isso comecei a me perguntar se não haveria uma direção por parte desse outro que iria interferir na minha "concepção". Com o decorrer das outras tentativas, percebi que esse olhar do outro, ou melhor, de outros poderiam 
me ajudar até mesmo a quebrar com essa minha "concepção" pré-estabelecida. Comecei a perceber que a presença de outra pessoa registrando também era um estímulo no momento de criação e que isso possibilitava que eu analisasse, posteriormente, os registros e descobrisse em cada fotografia uma nova possibilidade, além de já ir me acostumando com a presença de um interator. Com isso, busquei a cada tentativa deixar a vontade cada fotógrafo, permitindo-lhes registrar a sua maneira, mas em alguns momentos os dirigia para o meu olhar, para aquilo que eu estava buscando.

Contudo, a possibilidade de poder ver a fotografia logo após ela ter sido tirada facilitava que, no mesmo momento, eu (re) trabalhasse e (re)orientasse meu corpo para alcançar certos efeitos. Nesse sentido recorro às palavras de Andrade (2002, p. 54): "Aprendemos a ver apenas o que praticamente precisamos ver. Atravessamos nossos dias com viseiras, observando apenas uma fração do que nos rodeia. Os homens [...] não são bons observadores, e o uso da máquina fotográfica pode auxiliar sua percepção". Neste breve trecho a autora refere-se a nossa percepção num âmbito mais rotineiro de nossas vidas, porém em meu trabalho o uso da máquina fotográfica não somente ampliou meus horizontes como também permitiu que esse outro - fotógrafo - que me observava também estivesse observando a si mesmo, pois ao direcionar a máquina para certo enquadramento algo lhe estava chamando atenção e isso, de alguma forma, estaria falando algo de si mesmo. Olhando para o meu corpo, mas vendo o seu.

Dessa maneira, minha preocupação inicial com essa direção de olhar do outro se disseminou e abriu um leque de possibilidades que eu não atingiria se estivesse realizando tudo sozinha. Então passei a assumir a presença desses fotógrafos e de seus múltiplos olhares sobre um mesmo corpo, o nosso corpo.

Descobrindo a partir destes apontamentos anteriores que "existe uma distinção entre registrar e ver" (ANDRADE, 2002, p. 54) e estimulada pela análise e pelo exercício de "olhar" a partir do registro fotográfico dessa a "Tentativa 2 ", concentrei-me em elaborar o material para a "Tentativa 3". Mantinha-me realizando laminas com imagens eróticas da internet e buscando novos objetos para experimentar com as novas imagens selecionadas. A “Tentativa 3", ou, "O Vento Norte". Explico, o vento norte é um vento característico do Rio Grande do Sul que, quando ocorre, 
tem o poder de desnortear os sentidos, acometendo, de certa maneira o rumo das pessoas. É um "fenômeno" de difícil descrição e também não sei se há um embasamento científico sobre o assunto, mas quem já foi pego por um vento norte confirma minha história. Dessa maneira, enquanto que eu achava que minha pesquisa já tinha um rumo estabelecido, e já havia elaborado croquis do espaço que usaria na performance, fui acometida pelo vento norte. Durante a seleção prévia de imagens coloquei uma que me chamou muito a atenção e que não possuía um cunho erótico tão diretamente e, a partir de sua projeção em meu corpo é que os rumos mudaram totalmente.

A imagem que me refiro é de um corpo masculino (da cabeça até a pélvis) com indicações escritas das partes de seu corpo e linhas que delimitam e indicam essas partes, quase que uma figura de livros de anatomia, um estudo de temperamento. Nesse momento estava usando meu corpo como tela para a projeção e casualmente, a projeção deste corpo masculino se delimitou perfeitamente no meu. Assim, havia se criado uma confusão do meu corpo feminino com o "dele" masculino. Na seqüência coloquei uma meia-calça branca na cabeça, o que deixou o desenho do rosto "dele" nitidamente visível (Figura 02). Percebendo esses aspectos no momento da experimentação, pedi para a fotógrafa registrar meus movimentos.

A partir dessa experiência redefini e delimitei o campo de imagens que eu iria trabalhar em minha performance. Estabeleci que iria procurar imagens anatômicas do corpo humano. Na "Tentativa 4" além das imagens levei dois vídeos feitos por mim: o primeiro misturava imagens anatômicas de coração com fatos de tragédias históricas buscando causar um efeito de batida de coração e, o segundo vídeo, elaborado a partir de imagens de fetos sendo gerados misturados com imagens de crianças em diversas situações.

Assim, a "Tentativa 4" foi totalmente embasada nas imagens e idéias que eu já havia pré-estabelecido. Projetei o primeiro vídeo na posição onde fica o coração e o segundo vídeo na minha barriga, registrado por um fotógrafo. Projetei as lâminas com as outras imagens e fui buscando interagir com elas. Estabeleci que a meia-calça branca estaria presente de alguma maneira durante a pesquisa e na execução da performance. A partir da projeção de uma imagem cirúrgica busquei colocar meu corpo como tela, mas também criar a possibilidade desta cirurgia estar acontecendo comigo. Busquei deixar meu corpo neutro, pois acreditava que a neutralidade poderia salientar ainda mais o que eu estava querendo focar: meu corpo e a imagem, 
a relação que pode ser tecida, e não uma intervenção com ações e "emoções", pois não se trata de uma cena. Também busquei confundir meu corpo com a própria imagem, como por exemplo, confundir a minha própria mão com a mão do suposto cirurgião.

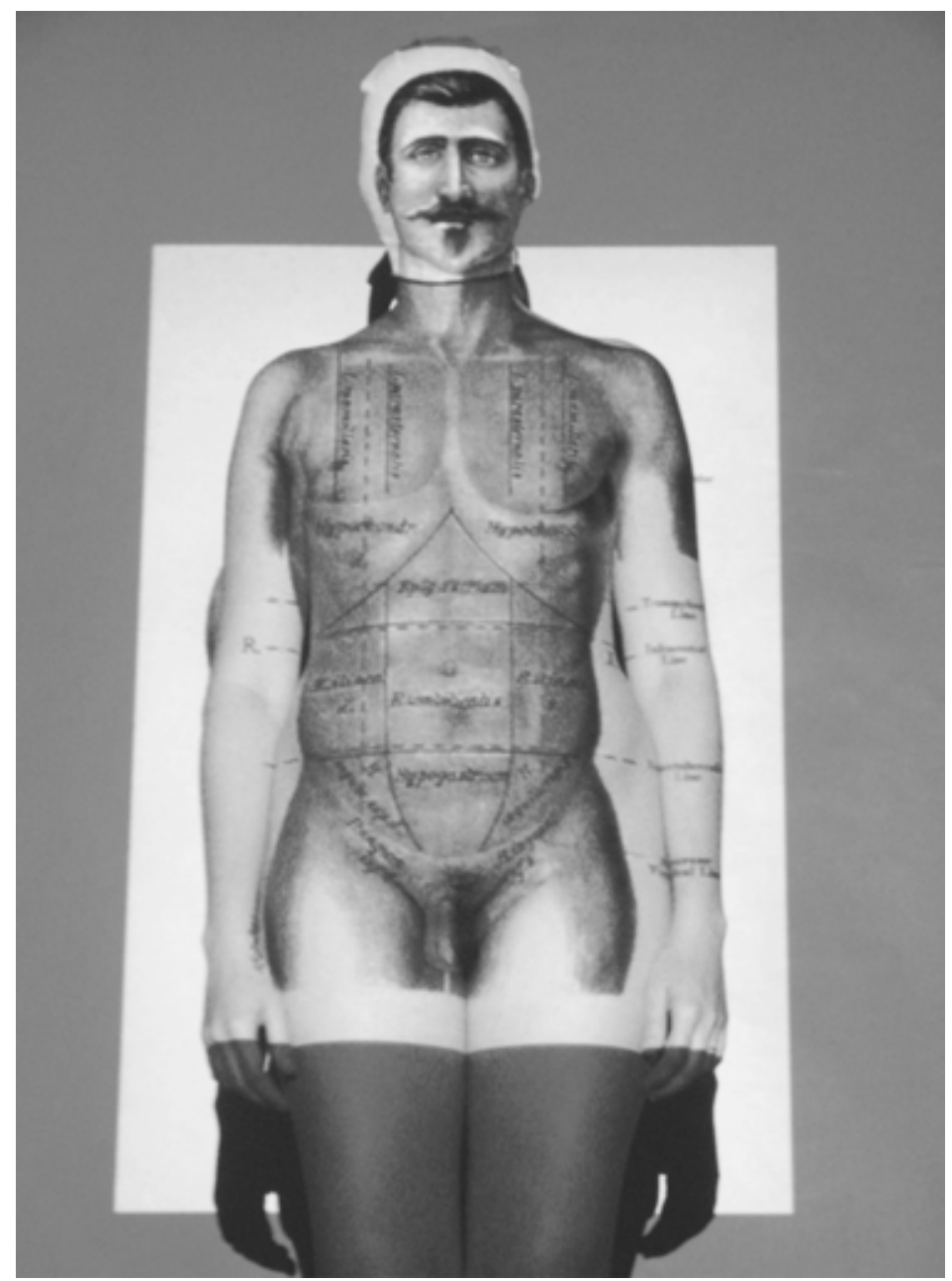

Figura o2 - O corpo como suporte de projeção

Acabei formando um arsenal de imagens de registro da pesquisa. Depois de muitas analises percebi que o que eu olhava era para uma nova epiderme. Não via mais o meu corpo, mas a pele 
que o (re)significava e (re)dimensionava enquanto suporte de mim mesma, eu extrapolava a verossimilhança conhecida.

A partir dessas novas possibilidades a estrutura da performance já tomava outro rumo. Foram várias as idéias que surgiram. Mas aos poucos, ia delineando o caminho voltando-me sempre para meus estudos teóricos sobre a performance art. Assim, tendo em mente que uma das características dessa expressão vinculase ao afloramento da percepção pelos sentidos: ocupei-me em contatar uma banda para explorar o elemento música juntamente com a elaboração da performance.

$\mathrm{Na}$ "Tentativa 5" projetei em meu rosto coberto pela meia calça diversos rostos de pessoas de ambos os sexos e de idades diferentes. O que eu buscava, era passar a idéia de mutabilidade que meu corpo assim como o corpo do outro pode desenvolver.

A partir de todo o material registrado e das sensações e idéias que surgiram a partir das "Tentativas" comecei a reestruturar os croquis da performance. Aos poucos fui elaborando, e montando o quebra-cabeça e buscando encontrar em cada "Tentativa" algo que pudesse permanecer na sua estrutura. Durante essa justaposição e colagem dos elementos comecei a questionar meu trabalho. Se considerarmos que a obra é uma espécie de labirinto com questões latentes, onde reside a potência de meu trabalho? Quais são as questões que o cercam? Qual o seu destino próprio? Contemporaneamente uma discussão recorrente diz respeito à originalidade da arte. Meu trabalho é original? Costumo pensar que o que faço, ou melhor, o que fazemos enquanto artistas hoje é exercer a montagem de um quebracabeças às avessas, ou seja, reordenar os elementos que já foram explorados e apresentados anteriormente. Não há originalidade, e sim, capacidade de (re)ordenação, uma repetição diferente. Nesse sentido, Deleuze nos coloca que toda obra é diferente repetição, a arte é o lugar no qual todas as repetições coexistem, mas só fortificam-se enquanto imagem que ultrapassa a obra, quando esta existe enquanto diferença:

[...] a diferença e a repetição tomaram o lugar do idêntico e do negativo, da identidade e da contradição, pois a diferença só implica a contradição na medida em que se continua a subordiná-la ao idêntico. O primado da identidade [...] define o mundo da representação. Mas o pensamento moderno nasce da falência da representação, assim como na perda de identi- 
dades e da descoberta de todas as forças que agem sob a representação do idêntico. $\mathrm{O}$ mundo moderno é o dos simulacros (DELEUZE, 2006, p. 15).

Assim como Deleuze, Dubois também visiona a falência da representação, quando aborda a desconstrução do discurso da transformação do real pela fotografia desenvolvida no século XIX por um discurso que transcende questões técnicas e liberta a fotografia, no século XX, de sua fixação empírica para atingir o princípio de uma verdade interior (1993, p. 37), bem como a ficção que ultrapassa a realidade interna.

Pensando até o momento em tudo isso que elucidei sobre meu processo criativo, agarro-me no pensamento borginiano de que é necessário compreender que um fracasso inicial é inevitável. Faço referência a esse fracasso devido a minha necessidade de afunilar os caminhos, de saber realmente qual é a potência disso, e principalmente, conseguir distanciar-me e colocar a imagem como "um outro" que não me pertence, que possuí um destino próprio e que fala por si. O que tentei, foi aclarar questões que estão surgindo usandome de referenciais teóricos como também das próprias inquietações que o processo de elaboração da performance está suscitando.

Refletindo sobre meu trabalho a partir desse relato, acredito que estava reduzindo o uso dos multimeios a projeções de imagens e filmes e deixando de lado outras possibilidades intrínsecas a ele.

Porém, tudo aqui são divagações de um corpo em estruturação, trazendo à tona questionamentos e incertezas que encontram abrigo no campo do invisível. Tornar esse invisível visível é um grande desafio a todos os artistas que transformam próprio corpo em sujeito e objeto de pesquisa, pois trabalha-se com aquilo que, aparentemente, não é concreto havendo a busca incessante de (des)cobrir qual é a bula do corpo não ficcional.

\section{Referências Bibliográficas:}

ANDRADE, Rosana. Fotografia e Antropologia: olhares fora e dentro. 2. ed. São Paulo: Estação Liberdade/ EDUC, 2002.

BORGES, Jorge Luis. Ficções. 2. ed. São Paulo: Companhia das Letras, $2007.169 \mathrm{p}$. 
COHEN, Renato. Performance como Linguagem. 2. ed. São Paulo: Perspectiva, 1989. 175 p.

DUBOIS, Philippe. O ato fotográfico e outros ensaios. 2. ed. São Paulo: Papirus, 1993. 362 p.

PLAZA, Julio; TAVARES, Monica. Processos criativos com os meios eletrônicos: poéticas digitais. 2. ed. São Paulo: Editora Hucitec, 1998.

DELEUZE, Gilles. Diferença e Repetição. 2. ed. Rio de Janeiro: Paz e Terra, 2006. $440 \mathrm{p}$.

\section{CLÁUDIA SCHULZ}

É Bacharel em Artes Cênicas - Habilitação em Interpretação Teatral e Habilitação em Direção Teatral - Universidade Federal de Santa Maria / Santa Maria - RS. Foi professora substituta do Curso de Artes Cênicas na Universidade Federal de Santa Maria, atualmente mestranda do Programa de Pós-Graduação em Artes Visuais da mesma instituição.

E-mail: claudiaxulzı@gmail.com

\section{LUCIANA HARTMANN}

É professora adjunta do Departamento de Artes Cênicas da UFSM. Doutora em Antropologia Social pela UFSC (2004), Mestre pela mesma universidade (2000) e Bacharel em Artes Cênicas pela UFRGS, realizou estágio doutoral na École des Hautes Études en Sciences Sociales/ Paris (2002-2003), vice-líder do GEPAEC.

E-mail: luhartm@yahoo.com.br 